\title{
A PESCA ARTESANAL NO BAIXO AMAZONAS: ANÁlise MULTIVARIADA DA CAPTURA POR ESPÉCIE.
}

\author{
Victoria Judith ISAAC ${ }^{1}$; Ana MILSTEIN ${ }^{2}$; Mauro Luis RUFFINO ${ }^{3}$
}

\begin{abstract}
RESUMO - Dados sobre esforço e captura por espécie correspondentes à produção pesqueira desembarcada no porto de Santarém, no ano de 1993, foram submetidos a duas técnicas de análise multivariada: uma análise de fatores segundo o método de componentes principais e outra de covariância conforme o modelo linear geral (GLM). Os resultados indicam que a atividade pesqueira na região está influenciada pelas características dos ciclos de vida das espécies-alvo, pelo ciclo hidrológico e condição climáticas de sistema, e ainda pelas preferências culturais e interesses econômicos do mercado consumidor. Os resultados indicam o direcionamento da atividade pesqueira para determinados grupos de espécies, e as diferentes variáveis incluídas no modelo permitiram uma explicação aproximada dos padrões desse direcionamento. Esses padrões são: (a) pesca de grandes bagres, alvo de pesca para a exportação (FATOR1); (b) pesca de entre-safra do mapará (Hypophthalmus spp.) e da pescada (Plagioscion spp.), realizada nos lagos com um componente para exportação e outro para o consumo local (FATOR4); (c) pesca de peixes de escamas de hábitos sedentários e/ou migratórios, alvo da pesca comercial de pequena escala e de importância no mercado local (FATOR2, FATOR3 e FATOR5), que inclui pescarias importantes como a do tambaqui (Colossoma macropomum) e do pirarucu(Arapaima gigas) nos lagos, ou a do jaraqui (Semaprochilodus spp.) e pacu (Mylossoma spp. e Metynnis spp.) nos rios.
\end{abstract}

Palavras-chave: pesca artesanal, Baixo Amazonas, dinâmica da pesca.

Artisanal Fishery in the Lower Amazon: Multivariate Analysis of the Catch by Species.

ABSTRACT - Effort and catch data per species making up for fisheries yield landed in 1993 in the city of Santarém were submitted to two techniques of multivariate analysis: a factor analysis by the principal components method and a covariance one using the general lineal model (GLM). Results suggest fishing activities in the region is influenced by the life cycle peculiarities of target species, by the water cycle and the weather conditions in the system, as well as by the cultural biases and economic interests of the consumer market. The results revealed the directioning of fishery activities toward certain groups of species, and those patterns were identified: (a) the fishing of large catfishes for export (FACTOR1); (b) the between-seasons fishing of mapará (Hypophthalmus spp.) and pescada (Plagioscion spp.) in lakes, with local and for export components (FACTOR4); (c) the fishing of sedentary and/or migratory scaled fishes, targeted by small-scale commercial fisheries with local importance (FACTOR2; FACTOR3 and FACTOR5), which includes important catches such as tambaqui (Colossoma macropomum) and pirarucu (Arapaima gigas) in the lakes, or jaraqui (Semaprochilodus spp.) and pacu (Mylossoma spp. and Metynnis spp.) in rivers.

Key-words: local fisheries, Lower Amazon, fisheries pattern

\section{INTRODUÇÃO}

A pesca artesanal na Amazônia brasileira é de vital importância para o fornecimento de alimento à população local e como fonte de renda, obtida através da comercialização do pescado nos mercados dos centros urbanos regionais e da exportação para o sul do país ou mesmo para o exterior.

\footnotetext{
I Museu Paraense Emílio Goeldi- Dpto. Zoologia, CP 399, Belém-PA, 66040-170, Brasil.

2 Fish and Aqualculture Research Station, Dor, MP Hof HaCarmel, 30820, Israel.

3 Projeto IARA (IBAMA/GTZ) Av. Tapajós, 2267, Santarém-PA, 68040-000, Brasil.
} 
O Médio Amazonas é a região que se estende ao longo do rio Amazonas e suas margens, desde a foz do rio Madeira até a foz do rio Xingu (Fig.1), A pesca praticada nesta região é de caráter artesanal. A captura de peixes é realizada com artes diversas, algumas bastante primitivas e de origem tradicional, e tem como alvo uma grande diversidade de espécies. Na parte paraense desta região, a atividade pesqueira é praticada por aproximadamente 30.000 pescadores profissionais e pelo menos o dobro de pescadores de subsistência (SUDEPE, 1988).

Poucas são as informações existentes sobre a pesca da região, fundamentalmente devido à falta de dados sistemáticos e contínuos para quantificar e caracterizar esta atividade. A pesca no Rio Madeira e na Amazônia Central foram analisadas à luz de informações de um ano de desembarques em Porto Velho e em Itacoatiara por GOULDING (1979) e SMITH (1979), respectivamente. Posteriormente, os desembarques na cidade de Manaus, no período entre 1976 e 1986 foram registrados e analisados por PETRERE (1978a, 1978b; 1985a) e por MERONA \& BITTENCOURT (1988; 1991). A pesca industrial da piramutaba Brachyplatystoma vaillantii, exercida no estuário amazônico, possui registros desde 1979 (IBAMA, 1994). Fora destes conjuntos de dados, não há outros registros confiáveis e disponíveis dos desembarques da pesca comercial na Amazônia. Informações sobre o desembarque nas cidades do Médio Amazonas nunca foram coletadas anteriormente de maneira sistemática.

O projeto IARA-Administração dos Recursos Pesqueiros na Região do Médio
Amazonas- tem por objetivo subsidiar a implementação de medidas de ordenamento que garantam o uso sustentável dos recursos pesqueiros (IBAMA, 1995). Este projeto iniciou atividades de coleta de informações sobre o desembarque pesqueiro, sobre a biologia dos peixes e sobre a situação sócio-econômica dos pescadores, desde 1991, fornecendo deste modo a base de dados necessária para realizar estudos sobre o estado de exploração dos estoques, com o objetivo de fazer recomendações sobre as formas mais viáveis de administração dos recursos pesqueiros. O presente trabalho apresenta os resultados da primeira análise realizada utilizando os dados do desembarque pesqueiro da cidade de Santarém do ano de 1993. O uso de técnicas estatísticas multivariadas visou a obtenção de uma imagem integrada da estrutura do sistema e dos fatores que principalmente caracterizam a atividade pesqueira, assim como a compreensão da forma de adaptação das técnicas usadas pelos pescadores às características biológicas e ecológicas das espécies alvo das pescarias e às mudanças ambientais.

\section{MATERIAL E MÉTODOS}

Os dados foram coletados diariamente, através de entrevistas com os donos ou encarregados das embarcaçốes que desembarcaram na cidade de Santarém, no ano de 1993. Cada registro de desembarque corresponde ao retorno de uma embarcação de uma pescaria. A produção e o esforço das pescarias foi qualificado e quantificado conforme as variáveis apresentadas nas Tabelas 1 e 2 . 


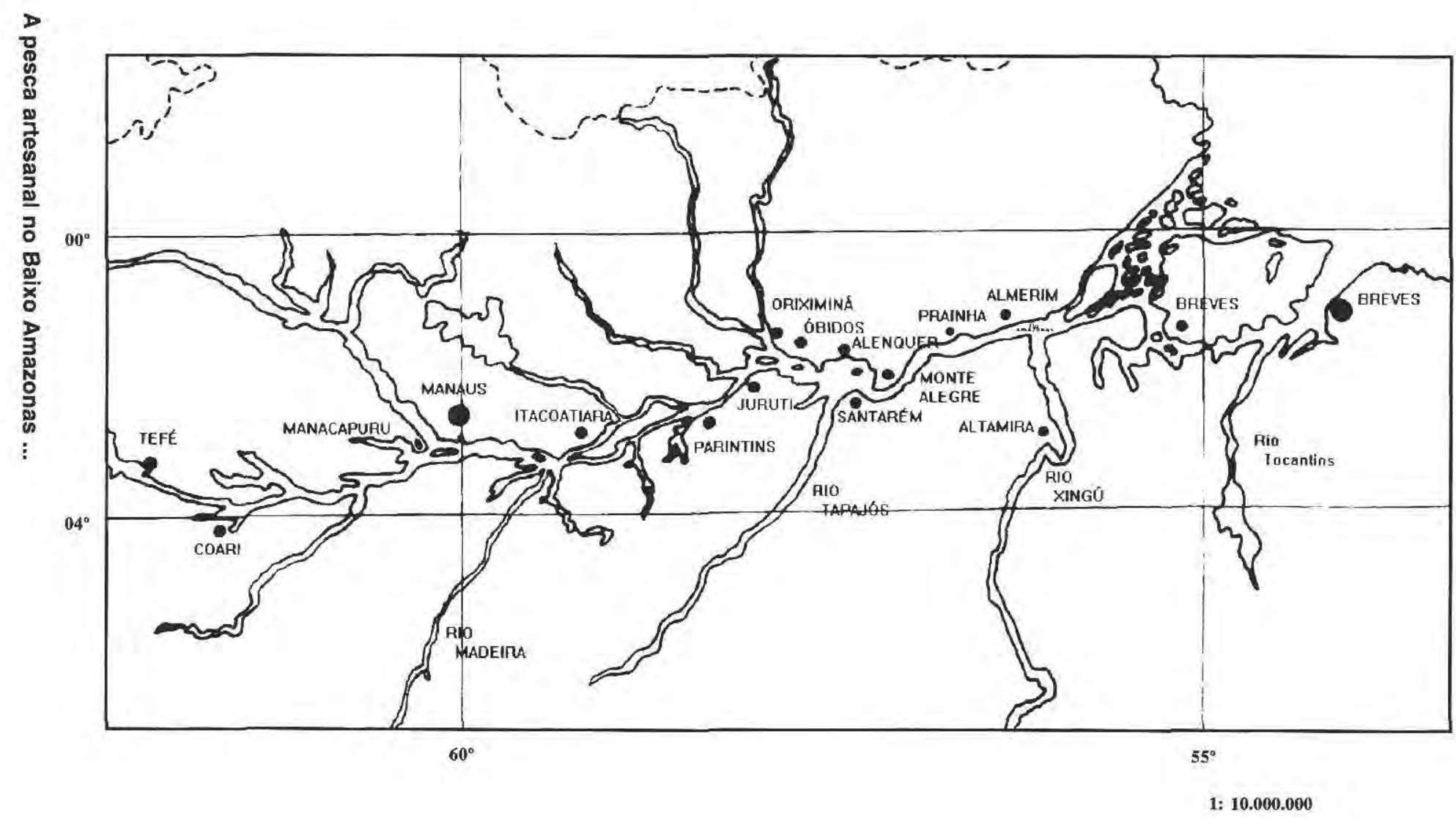

$\underset{\infty}{\infty} \quad$ Fifura 1. Mapa da região do Médio Amazonas 
Tabela 1. Nome, tipo e categorias das variáveis da matriz de dados de desembarque utilizadas nas análises do presente estudo. CAT= variável categórica. $\mathrm{NUM}=$ variável numérica.

\begin{tabular}{|c|c|c|}
\hline NOME & DESCRIÇÃO E CLASSES & TPO \\
\hline \multicolumn{3}{|c|}{ Variável explanatória } \\
\hline \multirow[t]{7}{*}{ Embarcação } & Tipo de embarcação & CAT \\
\hline & - Bp - barco pescador & \\
\hline & - Bc - barco comprador & \\
\hline & - Bm - barco misto & \\
\hline & - Bcl-barco de carga ou linha & \\
\hline & - C - canoa & \\
\hline & - Cm - canoa motorizada & \\
\hline Gelo & Quantidade de gelo consumido na viagem $(\mathrm{kg})$ & NMM \\
\hline Combustivel & Quantidade de combustíel consumida na viagem (1) & NMM \\
\hline \multirow[t]{5}{*}{ Distância } & Rank (1-4); distância entre minicípio de pesca e Santarém & CAT \\
\hline & -1 : Santarém, Alenquer, Monte Alegre & \\
\hline & -2 : Aveiros, Óbidos, Prainha, Terra Santa & \\
\hline & - 3 : Parintins, Oriximiná, Nhamundá, Trombetas & \\
\hline & - 4 : Mamaus, Itacoatiara, outros em Amazonas & \\
\hline Período & Período do dia em que ocoreu a pesca (dia, noite, ambos) & CAT \\
\hline \multirow[t]{5}{*}{ Ambiente } & Ambiente no local de pesca & CAT \\
\hline & $-L$ - Lago & \\
\hline & - R - Rio & \\
\hline & -Ig - Igarapé & \\
\hline & - Ip -Igapó & \\
\hline \multirow[t]{9}{*}{ Arte } & Tipos de aparelho(s) usados na pesca & CAT \\
\hline & - M - malhadeira & \\
\hline & -Mq-miqueira & \\
\hline & - LM - linhas & \\
\hline & - La - lance (arpão, zagaia, flecha) & \\
\hline & - Bb - bubuia & \\
\hline & - E-espinhel & \\
\hline & - T - tarrafa & \\
\hline & - $\mathrm{V}$ - mais de uma & \\
\hline Mês & Mês do desembarque & CAT \\
\hline Duração & Duração da viagem (dias) & NUM \\
\hline Pescadores & Número total de pescadores que participaram na pescaria & NUM \\
\hline \multirow[t]{5}{*}{ Mercado } & Local (mercado) de desembarque & CAT \\
\hline & - Md - Modelo & \\
\hline & - Ur - Uruará & \\
\hline & - M2 - Mercado 2000 & \\
\hline & - E-Frigorífico Edifrigo & \\
\hline
\end{tabular}


Tabela 2. Lista das categorias de espécies usadas na análise.

\begin{tabular}{|c|c|c|}
\hline \multirow[b]{2}{*}{ Grupo de espécie } & \multirow{2}{*}{\multicolumn{2}{|c|}{ Nomes comuns Nomes cientificos }} \\
\hline & & \\
\hline Acará & $\begin{array}{l}\text { acará-açu, acará-cascudo, acará. } \\
\text { bararuá, acará-bicudo, acará-disco, } \\
\text { acará-prata, acará-rosado, acará-rouxo } \\
\text { acaratinga }\end{array}$ & $\begin{array}{l}\text { Acarichthys heckelli, Acaronia nassa, Aequidens } \\
\text { sp. Astronotus crassipinis, Caquetaia spectabilis, } \\
\text { Chaetobranchus flavescens, Chaetobranchopsis } \\
\text { orbicularis, Cichlasoma, amazonarum, Geophagus } \\
\text { proximus, Heros sp., Satanoperca acuticeps, S. } \\
\text { jurupari, Symphysodon aequifasciatus, Uaru } \\
\text { amphiacanthoides }\end{array}$ \\
\hline Acarí-bodo & acarí-pedra, acarí-bodó & Hypostomos emarginatus, Liposarcus pardalis \\
\hline Apapá & apapá amarelo e apapá branco & Pellona falvipinis, $P$. castelnaeana \\
\hline Aracu & $\begin{array}{l}\text { aracu comum, aracu amarelo e aracu } \\
\text { cabeça gorda }\end{array}$ & $\begin{array}{l}\text { Leporinus aff. affinis } L \text {. fasciatus, } L \text {. friderici, } L \text {. } \\
\text { trifasciatus, Rhytiodus argenteofuscus, } R \text {. } \\
\text { microlepis, Schizodon fasctitus, S. vittatus }\end{array}$ \\
\hline Aruanā & aruanã & Osteogiossum bizirrosum \\
\hline Bacu & bacu liso e pedra & Pterodoras lentiginosus, Lithodoras dorsalis \\
\hline Barbado & barbado & Goslinia platynema \\
\hline \multirow[t]{2}{*}{ Branquinha } & branquinha comum, cascuda e cabeça & Caenotropus labirinthicus, Curimata inomata \\
\hline & lisa & $\begin{array}{l}\text { Cyphocharax abramoides, Psectrogaster } \\
\text { amazonica, } P \text {. rutiloides, Steindachnerina c.f. } \\
\text { bimaculata }\end{array}$ \\
\hline Charuto & charuto & $\begin{array}{l}\text { Anodus melanopogon, Hemiodus immaculatus, } H \text {. } \\
\text { microlepis, } H \text {. ocellatus, } H \text {. unimaculatus, } H \text {. sp. }\end{array}$ \\
\hline Cujuba & cujuba & Oxydoras niger \\
\hline Curimatã & curimatã & Prochilodus nigricans \\
\hline Dourada & dourada & Brachyplatystoma flavicans \\
\hline Filhote & filhote e piraiba & Brachyplatystoma filamentosum \\
\hline Fura calça & fura calça & $\begin{array}{l}\text { Pimelodina flavipinnis, Pimelodus cf. altipinnis, P. } \\
\text { blochii }\end{array}$ \\
\hline Jaraqui & jaraqui escama fina e escama grossa & Semaprochilodus teanurus, $S$. insignis \\
\hline Jaú & jaú & Paulicea luetkeni \\
\hline Mapapá & mapapá & $\begin{array}{l}\text { Hypophthaimus edentatus, } H \text {. fumbriatus, } H \text {. } \\
\text { marginatus }\end{array}$ \\
\hline Pacu & pacu comum, jumento e olhudo & $\begin{array}{l}\text { Catoprion mento, Metynnis argenteus, } M \text {. } \\
\text { hypsauchen, Myleus schomburgki, } M \text {. torquatus, } \\
\text { Mylossoma aureum, } M \text {. duriventre }\end{array}$ \\
\hline Pescada & pescada comum e preta & $\begin{array}{l}\text { Pachypops furchraeus, } P \text {. trifilis, Plagioscion } \\
\text { auratus, } P \text {. squamosissimus, } P \text {, surinamensis, } P . s p\end{array}$ \\
\hline Piranha & $\begin{array}{l}\text { piranha branca. caju, mafurá, mucurá } \\
\text { e preta }\end{array}$ & $\begin{array}{l}\text { Pygocentrus nattereri, Serrasalmus calmoni, S. } \\
\text { elongatus, S. mombeus, S. spilopleura, S. aff. } \\
\text { eigenmmanni }\end{array}$ \\
\hline Pirarara & pirarara & Phractocephalus hemioliopterus \\
\hline Pirarucu & pirarucu & Arapaima gigas \\
\hline Piramutaba & piramutada & Brachyplathystoma vaillantii \\
\hline Pirapitinga & pirapitinga & Piaractus brachypomus \\
\hline Sardinha & sardinha comum, comprida e papuda & Triportheus albus, T. elongatus, $T$. flavus \\
\hline Surubim & $\begin{array}{l}\text { surubim palhaço, surubuim flamengo, } \\
\text { surubim lenha ou canela, surubim tigre } \\
\text { ou pintado }\end{array}$ & $\begin{array}{l}\text { Brachyplatystoma juruensi, Merodontotus tigrinus, } \\
\text { Pseudoplatystoma fasciatus, P. tigtrinus, }\end{array}$ \\
\hline Tambaqul & tambaqui & Colossoma macropomum \\
\hline Traíra & traíra, & Hoplias gr. malabaricus \\
\hline Tucunaré & tucunaré comum, açu, pinima & Cichla sp, C. monoculus, C. temensis \\
\hline
\end{tabular}


Inicialmente foram registradas 63 espécies diferentes de peixes e crustáceos. Com a finalidade de simplificar a análise e seguindo o critério dos pescadores, na classificação de espécies similares a bordo das embarcações, as capturas de algumas espécies afins foram agrupadas. Por exemplo, a produção de tucunaré açu, tucunaré pinima e tucunaré comum foi somada sob a categoria "tucunaré". Por último, as espécies que ocorreram em menos de 40 desembarques foram eliminadas da matriz de dados, por serem consideradas espécies raras. Por estes procedimentos, as 63 espécies foram reduzidas para 29 grupos (Tab.2).

Com os dados construiu-se uma matriz, onde cada linha representa uma viagem e as colunas os valores de captura/viagem (transformados a $\log 10$ para obter normalidade) para cada categoria de espécies (29), além de dados sobre o esforço pesqueiro e outras características da pescaria (11).

Inicialmente, a parte da matriz contendo os dados de captura/viagem por categoria de espécie (6.606 linhas x 29 colunas) foi submetida a um análise multivariada de fatores. Esta técnica visa, evidenciar uma estrutura latente nos dados, reduzindo o grupo original de variáveis a um novo grupo, chamadas "fatores". Os fatores são funções linhares das variáveis originais, e refletem a correlação existente entre elas. Os valores das novas variáveis, são estimados calculando a somatória de cada uma das variáveis originais multiplicadas pelo coeficiente correspondente, calculado pelo ajuste de um modelo do tipo:

FATOR $n=$ VAR $1 *$ coef_nVAR 1 + VAR $2 *$ coef_nVAR $2+\ldots .+$ VAR $29 *$ coef_nVAR 29 , onde: VAR1, VAR2, etc, representam os logaritmos das captura/viagem para cada espécie e coef_n, o valor do coeficiente do FATORn, para cada variável.

O modelo é resolvido através do método dos componentes principais. A análise é feita a partir de uma matriz de correlação e com uma finalidade exploratória e não preditiva. Assumese que os fatores são responsáveis pela co-variação observada entre as capturas das diferentes espécies. $\mathrm{O}$ primeiro fator obtido representa a combinação linear das variáveis originais, que melhor explica a variação contida nos dados. $\mathrm{O}$ segundo fator explica a maior quantidade da variação restante, e assim por diante. Os fatores são independentes uns dos outros, não possuem unidades e são variáveis padronizadas (média $=0$, variância $=1$ ) e com distribuição normal. Os coeficientes obtidos para cada espécie foram usados para interpretar a afinidade entre espécies e o significado dessa afinidade no contexto da ecologia pesqueira da região. $\mathrm{O}$ sinal e o valor de cada coeficiente é um indicador da importância de cada espécie dentro do fator. Dentro de cada fator, os coeficientes calculados apresentam valores positivos para algumas espécies e negativos para outras. As espécies com o mesmo sinal estão correlacionadas entre si (ocorrem juntas) e aquelas cujos coeficientes tem sinais diferentes apresentam uma correlação negativa, ou seja, apresentam dominância oposta. A Tabela 4 apresenta os coeficientes 
obtidos para os cinco primeiros fatores, assim como a variância explicada por cada um. Os coeficientes menores que 0,30 foram excluídos da tabela, apenas para facilitar a visualização dos resultados.

Dos 29 fatores resultantes foram escolhidos apenas os primeiros 5 para serem utilizados nas análises a seguir, pois eram os que melhor se ajustavam aos conhecimentos existentes sobre a ecologia pesqueria da região.

Os efeitos das diferentes características das pescarias sobre as novas variávies assim definidas foram testado através do Modelo Linear Geral (GLM), usado como uma análise de co-variância não balanceado (ANCOVA). Para esta análise foi utilizada a matriz de 6.606 observações. O modelo foi ajustado separadamente para cada um dos primeiros cinco fatores, os quais foram utilizados como variáveis dependentes. Como variáveis explanatórias, ou independentes, foram consideradas as características da pescaria, incluindo o número de pescadores, a duração da viagem, a quantidade de óleo diesel e gelo consumido em cada viagem (variáveis numéricas), e a arte de pesca utilizada, o tipo de barco, o local de pesca, a distância relativa do local de pesca até Santarém, o período do dia em que foi realizada a pescaria e o mês do ano (variáveis categóricas) (Tab. 1). Os valores das variáveis numéricas foram transformados a $\log 10$ para obter normalidade. A soma dos quadrados dos desvios, os quadrados médios, e o valor de F foram calculados para cada variável. A partir da soma dos quadrados total, calculou-se a porcentagem que correspondia a variabilidade de cada variável, o que foi usado como medida do peso de cada variável no modelo geral. A tabela 5 mostra os coeficientes de determinação $\left(\mathrm{R}^{2}\right)$ obtidos no GLM, calculados independentemente para cada fator, assim como a porcentagem da soma dos quadrados dos desvios de cada variável explanatória.

Por último, as médias de cada fator para cada nível das variáveis categóricas, tomadas independentemente uma do outra, foram calculadas e testadas com o teste de comparação múltipla de Duncan (multiple range test). Diferenças significativas ao nível de $\mathrm{P}=0,05$ foram indicadas por letras diferentes, onde $\mathrm{A}>\mathrm{B}>\mathrm{C}>\mathrm{D}>\mathrm{F}$ (Tab. 6).

As análises foram realizadas utilizando as rotinas FACTOR e GLM do pacote SAS (1987). Descrição mais detalhada das técnicas estatísticas utilizadas pode ser obtida em SEAL (1964), LEFEBVRE (1976), JEFFERS (1978), KIM \& MUELLER (1978), PREIN \& MILSTEIN (1988), SCHUEMER et al. (1990) e MILSTEIN (1993).

\section{RESULTADOS}

No ano de 1993 obteve-se um total de 7.676 registros de desembarque dos quais apenas 6.606 possuiam todas as informações completas. Além de uma grande quantidade de canoas a remo, mais de 1000 embarcações diferentes aportaram na cidade nesse ano, incluindo canoas motorizadas, barcos geleiros e barcos de transporte de passageiros ou carga. De acordo com a sua função no processo da captura e transporte de pescado, os barcos geleiros podem ser classificados em barco pescador, que conduz uma equipe mais ou menos fixa de pescadores até os locais de pesca, barco comprador que 
somente se desloca para comprar pescado, que foi capturado por diferentes pescadores locais e barco misto, que tanto possui uma tripulação fixa de trabalhadores que pescam junto ao barco, como compra peixe para completar a sua capacidade de carga. As artes de pesca foram classificadas em 8 categorias, a saber:

- malhadeira:rede de emalhar de nylon multifilamento com malhas variadas;

- miqueira: rede de emalhar de nylon monofilamento com malhas variadas;

- bubuia: rede de emalhe longa e alta, colocada à deriva no meio do rio;

- tarrafa: rede cônica com bordas equipadas com chumbo;

- linhas: linha de nylon comprida, com um anzol na ponta, utilizada na mão, amarrada a vara de madeira ou presa $a$ ponto fixo na margem;

- espinhel: uma linha comprida com vários anzóis;

- artes de lançar: podem ser três aparelhos distintos: arpão, arco e flexa ou zagaia que é uma haste de madeira com ponta metálica afiada;

- mais de uma: combinação de diferentes artes de pesca utilizadas durante uma pescaria.

A produção total de pescado comercializada na cidade de Santarém em 1993 foi de 4.280 t (Tab. 3). Mais de 60 espécies diferentes de peixes foram comercializadas nos portos, embora apenas 10 espécies representam cerca de $80 \%$ do total em peso. Os desembarques mensais variaram de $170 \mathrm{t}$ a $850 \mathrm{t}$, dependendo da época do ano e do nível do rio. A oscilação média do nível do rio devido às enchentes é unimodal ao longo do ano, e apresentou um máximo em maio ( $8 \mathrm{~m})$ e mínima em novembro (3 m) (Tab.3). A captura média por viagem de pesca foi em torno de 380 $\mathrm{kg}$, para uma duração média de 3 a 4 dias de viagem. O preço médio de primeira comercialização variou entre US\$ $0,13 / \mathrm{kg}$ e US $\$ 1,42 / \mathrm{kg}$, dependendo da espécie e da época do ano, com uma média de US\$ $0,50 / \mathrm{kg}$ (Tab. 3). Aproximadamente $50 \%$ do peixe desembarcado foi comercializado no frigorífico Edifirigo e o restante dividese entre os outros três portos da cidade (Modelo, 2000 e Uruará), onde se instalam diaramente feiras nas quais a produção é comercializada para o consumo local.

O primeiro fator destaca espécies que constituem a maior biomassa nas capturas da região, aparecendo como o grupo mais definido dentro do sistema. Responsável por $11 \%$ da variabilidade dos dados (Tab.4), o primeiro fator é caracterizado pela dominância dos bagres (genericamente conhecidos como "peixes lisos") da familia dos Pimelodidae, que são o principal alvo da pesca profissional e que desembarca nos frigoríficos. Destacam-se a dourada (Brachyplatystoma flavicans), o filhote (B. filamentosum), a piramutaba (B. vaillantii), o jaú (Paulicea luetkeni) e os surubins (Pseudoplatystoma tigrinus e $P$. fasciatum) e outras espécies de menor importância. As características da pesca consideradas no modelo são responsáveis por $63 \%$ da variabilidade do FATOR1 (Tab. 5). Os valores relativos à soma dos quadrados dos desvios indicam que o mercado e o tipo de arte utilizado na pescaria são as características que mais influenciam este grupo. Os barcos 
Tabela 3. Nível médio mensal do rio (m) Tapajós, captura e preço médio da primeira comercialização, por categoria de espécies e por mês, para a produção pesqueira desembarcada no porto de Samtarém no ano de 1993. Para cada espécie a primeira linha corresponde ao desembarque $(\mathrm{kg})$ e a segunda ao preço médio (US\$ $/ \mathrm{kg}$ ).

\begin{tabular}{|c|c|c|c|c|c|c|c|c|c|c|c|c|c|}
\hline ESPÉCIE & JAN & FEV & MAR & ABR & MAI & JUN & JUL & AGO & SET & OUT & NOV & DEZ & TOTAL \\
\hline \multirow[t]{2}{*}{ Acará } & 8410 & 3203 & 4426 & 741 & 478 & 724 & 1096 & 3122 & 1152 & 7499 & 5397 & 3997 & 40245 \\
\hline & 0,68 & 0,51 & 0,47 & 0,78 & 0,52 & 0,55 & 0,54 & 0,44 & 0,37 & 0,37 & 0,39 & 0,66 & 0,52 \\
\hline \multirow[t]{2}{*}{ Acari-bodó } & 7394 & 4428 & 5852 & 3975 & 221 & 2371 & 6577 & 7177 & 651 & 354 & 6650 & 13576 & 59226 \\
\hline & 0,29 & 0,21 & 0,26 & 0,29 & 0,25 & 0,63 & 0,38 & 0,41 & 0,41 & 0,31 & 0,28 & 0,38 & 0,34 \\
\hline \multirow[t]{2}{*}{ Apapá } & 1838 & 926 & 2039 & 2312 & 1619 & 3218 & 3048 & 5139 & 6607 & 4752 & 2909 & 4281 & 38688 \\
\hline & 1,08 & 0,46 & 0,55 & 0.72 & 0,57 & 0,52 & 0,59 & 0,50 & 0,42 & 0,37 & 0,39 & 0,89 & 0,59 \\
\hline
\end{tabular}

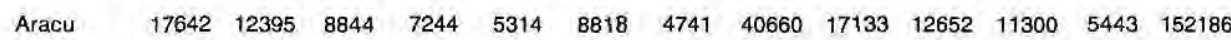

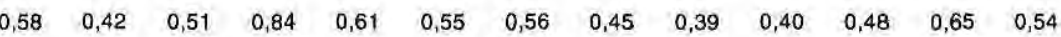

$\begin{array}{llllllllllllll}\text { Aruanã } & 798 & 703 & 565 & 101 & 10 & 4 & 290 & 638 & 820 & 5306 & 5776 & 3724 & 18735\end{array}$

$\begin{array}{lllllllllllll}0,37 & 0,26 & 0,31 & 0,62 & 0,30 & 0,32 & 0,40 & 0,35 & 0,34 & 0,27 & 0,22 & 0,28 & 0,347\end{array}$

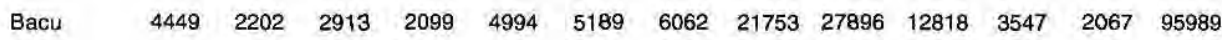

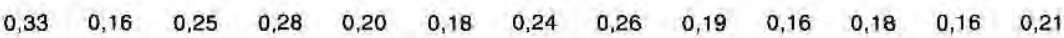

$\begin{array}{llllllllllllll}\text { Barbado } & 48 & 36 & 370 & 817 & 1854 & 1754 & 1979 & 4001 & 4680 & 7124 & 3510 & 352 & 26525\end{array}$

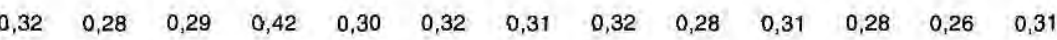

$\begin{array}{llllllllllllll}\text { Branquinha } & 275 & 77 & 109 & 0 & 0 & 15 & 109 & 44 & 10 & 7 & 510 & 503 & 1659\end{array}$

$\begin{array}{llllllllllllll}0,63 & 0,35 & 0,24 & \cdots & \cdots & 0,58 & 0,38 & 0,41 & 0,28 & 0,27 & 0,37 & 0,86 & 0,44\end{array}$

$\begin{array}{llllllllllllll}\text { Charuto } & 1986 & 154 & 215 & 235 & 109 & 477 & 504 & 544 & 329 & 365 & 988 & 268 & 6174\end{array}$

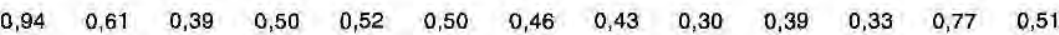

$\begin{array}{llllllllllllll}\text { Cujuba } & 12761 & 8107 & 4904 & 2105 & 570 & 42 & 618 & 3363 & 16549 & 7878 & 4066 & 6767 & 67730\end{array}$

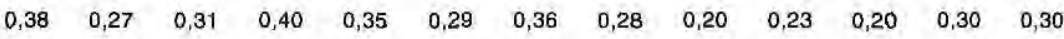

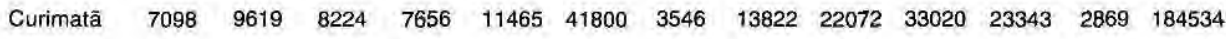

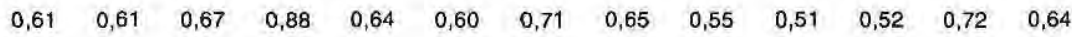

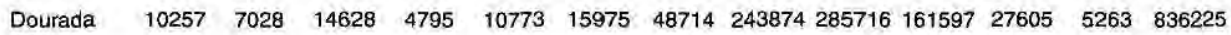

\begin{tabular}{lccccccccccccc} 
& 0,75 & 0,80 & 0,80 & 1,01 & 0,70 & 0,70 & 0,67 & 0,55 & 0,53 & 0,44 & 0,45 & 0,57 & 0,66 \\
Filhote & 1300 & 1757 & 6048 & 4994 & 6727 & 9635 & 16679 & 33574 & 44070 & 23156 & 5919 & 2631 & 156490 \\
& 0,61 & 0,80 & 0,79 & 1,07 & 0,73 & 0,67 & 0,65 & 0,57 & 0,51 & 0,46 & 0,50 & 0,63 & 0,68 \\
\multirow{2}{*}{ Fura calça } & 570 & 705 & 1278 & 1958 & 4998 & 2118 & 5266 & 1417 & 0 & 0 & 0 & 600 & 18910 \\
& 0,30 & 0,40 & 0,30 & 0,43 & 0,38 & 0,31 & 0,41 & 0,28 & - & - & 0,54 & 0,37 & 0,37 \\
& 58 & 200 & 18394 & 23268 & 202203 & 56046 & 2539 & 5742 & 1917 & 2340 & 5063 & 4018 & 339088 \\
Jaraqui & & 0,72 & 0,77 & 0,83 & 0,64 & 0,55 & 0,64 & 0,43 & 0,32 & 0,39 & 0,45 & 0,65 & 0,58
\end{tabular}


cont. Tabela 3.

\begin{tabular}{cccccccccccccc}
\hline Jaú & 414 & 1103 & 1206 & 432 & 673 & 1111 & 2210 & 9823 & 13279 & 4176 & 1002 & 383 & 35812 \\
& & - & 0,30 & 0,34 & 0,32 & 0,34 & 0,36 & 0,28 & 0,27 & 0,25 & 0,20 & 0,24 & 0,29
\end{tabular}

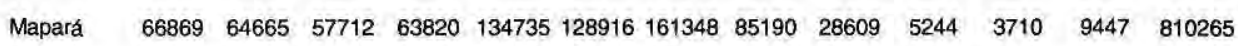

\begin{tabular}{|c|c|c|c|c|c|c|c|c|c|c|c|c|c|}
\hline & 0,39 & 0,30 & 0,31 & 0,40 & 0,33 & 0,35 & 0,35 & 0,26 & 0,24 & 0,20 & 0,20 & 0,57 & 0,33 \\
\hline \multirow[t]{2}{*}{ Pacu } & 1421 & 1645 & 3042 & 5264 & 2119 & 5585 & 756 & 20058 & 29140 & 26348 & 6610 & 672 & 102660 \\
\hline & 0,76 & 0,45 & 0,54 & 0,82 & 0,58 & 0,55 & 0,58 & 0,44 & 0,41 & 0,42 & 0,46 & 0,72 & 0,56 \\
\hline \multirow[t]{2}{*}{ Pescada } & 14231 & 18688 & 12655 & 16617 & 14554 & 18523 & 27318 & 27957 & 30810 & 35969 & 40167 & 28864 & 286353 \\
\hline & 0,58 & 0,44 & 0,52 & 0,74 & 0,53 & 0,53 & 0,60 & 0,49 & 0,42 & 0,42 & 0,48 & 0,57 & 0,53 \\
\hline \multirow[t]{2}{*}{ Piramulaba } & 561 & 833 & 551 & 252 & 378 & 351 & 787 & 96008 & 84270 & 19183 & 1265 & 33425 & 237864 \\
\hline & 0,34 & 0,39 & 0,33 & 0,30 & 0,34 & 0,29 & 0,35 & 0,32 & 0,34 & 0,28 & 0,27 & 0,25 & 0,32 \\
\hline \multirow[t]{2}{*}{ Piranha } & 183 & 0 & 141 & 361 & 162 & 933 & 187 & 288 & 63 & 129 & 556 & 339 & 3342 \\
\hline & 0,21 & - & 0,28 & 0,43 & 0,30 & 0,32 & 0,25 & 0,18 & 0,16 & 0,13 & 0,15 & 0,19 & 0,30 \\
\hline \multirow[t]{2}{*}{ Pirapitinga } & 20 & 10 & 74 & 2953 & 509 & 1844 & 243 & 15745 & 1044 & 1962 & 1189 & 452 & 26045 \\
\hline & 1.07 & 0,39 & 0,47 & 0,91 & 0,66 & 0,63 & 0,60 & 0,46 & 0,40 & 0,38 & 0,46 & 0,77 & 0,60 \\
\hline \multirow[t]{2}{*}{ Pirarara } & 1406 & 860 & 657 & 309 & 1173 & 592 & 1316 & 12554 & 13495 & 8963 & 2991 & 1702 & 46018 \\
\hline & 0,37 & 0,30 & 0,32 & 0,38 & 0,42 & 0,34 & 0,39 & 0,30 & 0,27 & 0,24 & 0,26 & 0,33 & 0,33 \\
\hline \multirow[t]{2}{*}{ Pirarucu } & 570 & 486 & 1176 & 1082 & 439 & 282 & 722 & 2534 & 3725 & 5837 & 2772 & 504 & 20129 \\
\hline & 1,15 & 0,84 & 1.12 & 1,42 & 1,03 & 1,16 & 1,20 & 1,11 & 0,98 & 0,90 & 0.92 & 1,06 & 1,07 \\
\hline \multirow[t]{2}{*}{ Sardinha } & 178 & 0 & 0 & 0 & 45 & 0 & 2 & 418 & 248 & 444 & 66 & 260 & 1661 \\
\hline & 0,78 & - & - & - & 0,69 & - & 0,48 & 0,51 & 0,33 & 0,38 & 0,20 & 0,89 & 0,53 \\
\hline
\end{tabular}

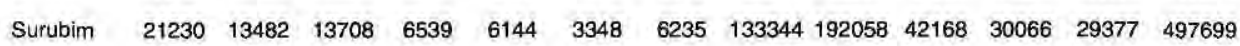

$\begin{array}{lllllllllllll}0,74 & 0,73 & 0,90 & 1,12 & 0,76 & 0,73 & 0,68 & 0,59 & 0,53 & 0,46 & 0,49 & 0,65 & 0,70\end{array}$

$\begin{array}{llllllllllllll}\text { Tambaqui } & 10684 & 14906 & 16044 & 29073 & 9507 & 4926 & 3658 & 9133 & 8361 & 7090 & 8716 & 3055 & 125153\end{array}$

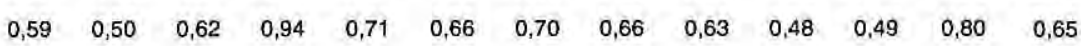
$\begin{array}{llllllllllllll}\text { Tamuatá } & 752 & 117 & 0 & 19 & 0 & 223 & 1689 & 10 & 0 & 147 & 19 & 0 & 2976\end{array}$

$\begin{array}{llllllllllllll}\text { Traira } & 69 & 5 & 8 & 572 & 3 & 29 & 565 & 0 & 14 & 813 & 1035 & 582 & 3695\end{array}$ $\begin{array}{lllllllllllll}0,46 & 0,55 & 0,18 & 0,42 & 0,41 & 0,32 & 0,26 & - & 0,21 & 0,24 & 0,19 & 0,26 & 0,32\end{array}$

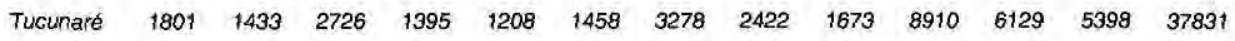

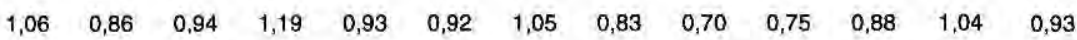

CAPTURA
TOTAL 1952901697851885221910054229983163223120988003678537014462622128881708344280072

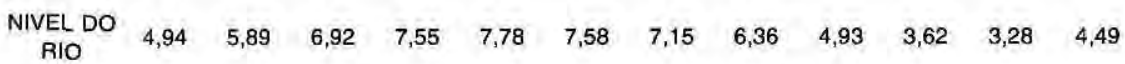


contendo maiores tonelagens de bagres comercializam a produção principalmente no frigorífico Edifrigo. As maiores capturas de bagres são obtidas com bubuia e espinhel, em ambientes lóticos de rios ou igarapés (Tab.6). Os meses de safra de peixe liso coincidem com o período de águas baixas, entre julho e outubro, particularmente no mês de setembro (Tab.3). A pesca de bagres é mais produtiva em municípios relativamente distantes de Santarém, como Parintins, Oriximiná, Nhamundá e Trombetas. O barco misto, ou seja, aquele que compra peixe de outros pescadores e também leva sua própria equipe de profissionais para pescar, apresentou desembarques com maiores capturas de bagres que os outros tipos de embarcações (Tab. 6).

O segundo fator explica cerca de $6 \%$ da variabilidade dos dados da captura das espécies e é caracterizado pela dominância de peixes de hábitos sedentários, tais como aruanã (Osteoglosum bicirrhosum), tucunarés (Cichla spp.), acarás (dos gêneros Astronotus, Geophagus e Cichlasoma), traíras (Hoplias spp.). Também destacam-se espécies que não migram durante a sua fase juvenil e como adultos permanecem uma parte do ano em ambientes lênticos e outra parte migrando nos rios, tais como o tambaqui (Colossoma macropomum), o curimatã (Prochilodus nigricans) e os surubins (Tab. 4). As características da pesca consideradas no modelo são responsáveis pelo $28 \%$ da variabilidade deste fator, sendo o mercado, o tipo de arte utilizada na pescaria e o mês da captura, as características que mais afetam o
FATOR2 (Tab. 5). O grupo de espécies deste fator caracteriza-se por ser comercializado principalmente nos mercados locais, Modelo e Uruará. A produção foi alta quando utilizadas artes como o arpão, a zagaia ou a flecha, mas a pesca com malhadeira também é boa e muito mais freqüente. A produção por viagem é elevada bem no início da subida do nível do rio, especialmenteentre novembro e dezembro. As maiores capturas provém de locais a distâncias médias de Santarém (Tab. 6).

$\mathrm{O}$ terceiro fator explica cerca de $5 \%$ da variabilidade da composição específica do desembarque (Tab.4). Este fator apresenta bi-polaridade, reunindo dois grupos de espécies negativamente correlacionadas entre si. Com coeficientes positivos ocorrem espécies de tamanho pequeno ou médio, como acará, tucunaré, jaraqui (Semaprochilodus insignus e $S$. taeniurus), e o charuto (Hemiodus sp.). Com exceção do tucunaré, estas espécies possuem um baixo preço na sua comercialização (Tab. 3). $O$ jaraqui e o charuto possuem como característica principal o seu comportamento migratório, em forma de cardumes, no fim da estação das chuvas. A pescaria do jaraqui é muito específica, e os desembarques desta espécie em Santarém estão diretamente associados a este comportamento migratório e, por isso, säo restritos no tempo. Os coeficientes negativos pertencem ao tambaqui e ao pirarucu (Arapaima gigas), peixes de escama de bom tamanho e alto valor de comercialização no mercado local. As características da pesca incluídas no modelo explicam apenas $23 \%$ da variabilidade do FATOR3, sendo o 
Tabela 5. Resultados do GLM e $\mathrm{R}^{2}$ para os primeiros 5 fatores. Os valores representam a \% da soma total dos quadrados dos desvios de cada fator e os asteriscos o nível de significância de cada fonte de variação, onde $* * *=0.01 \mathrm{e}^{* *}=0.05$. O signo da correlação de todas as variáveis contínuas é positiva para todos os fatores.

\begin{tabular}{|c|c|c|c|c|c|c|c|c|c|c|}
\hline & & & & & & & & & & \\
\hline & 1 & & 2 & & 3 & & 4 & & 5 & \\
\hline R2 & 0.63 & & 0.28 & & 0.23 & & 0.30 & & 0.08 & \\
\hline GELO & 0.05 & ns & 1.65 & $* * *$ & 0.13 & ns & 1.38 & $* * *$ & 1.53 & ns \\
\hline CONBUSTIVEL & 1.48 & $* * *$ & 0.02 & ns & 0.09 & ns & 4.45 & *** & 1.06 & ** \\
\hline DURAÇÃO & 0.05 & ns & 0.24 & ns & 0.09 & ns & 0.87 & $* * *$ & 0.40 & ns \\
\hline PESCADORES & 0.54 & $* * *$ & 1.09 & $* * *$ & 0.00 & ns & 1.78 & $* * *$ & 2.95 & $* * *$ \\
\hline EMBARCAÇÃO & 2.71 & $* * *$ & 0.61 & ns & 4.90 & $* * *$ & 7.19 & $* * *$ & 2.90 & $* *$ \\
\hline DISTÂNCIA & 4.27 & $* * *$ & 9.57 & $* * *$ & 3.86 & $* * *$ & 12.6 & $* * *$ & 11.4 & $* * *$ \\
\hline PERIOODO & 0.84 & $* * *$ & 1.00 & $* * *$ & 1.96 & $* * *$ & 2.62 & *** & 2.05 & $* * *$ \\
\hline AMBIENTE & 2.18 & $* * *$ & 4.13 & $* * *$ & 10.2 & $* * *$ & 30.5 & $* * *$ & 4.87 & *** \\
\hline ARTE & 35.1 & $* * *$ & 27.5 & $* * *$ & 25.3 & $* * *$ & 19.4 & $* * *$ & 21.4 & $* * *$ \\
\hline MÊS & 3.29 & $* * *$ & 24.1 & $* * *$ & 17.2 & $* * *$ & 12.4 & $* * *$ & 23.5 & n*** \\
\hline MERCADO & 49.5 & $n * *$ & 29.9 & $* * *$ & 36.1 & $* * *$ & 6.59 & $* * *$ & 27.8 & $* * *$ \\
\hline
\end{tabular}

(FATOR4 negativo) é capturado de forma mais artesanal, utilizando canoas e comercializado no Mercado Uruará, onde são freqüentes os desembarques da pesca de menor escala (Tab. 6).

$O$ quinto fator explica cerca de $4 \%$ da variabilidade dos dados das capturas por espécie (Tab. 4). Está formado também por dois grupos negativamente correlacionados. Nos peixes do FATOR5 positivo, destacam-se pirapitinga (Piaractus brachypomus), branquinha (gêneros Potamorhyna e Curimata) e charuto, que realizam migrações dispersivas e reprodutivas durante a estação da seca (piracema). As espécies do FATOR5 negativo estão representados pela traíra, aruanã e acaríbodo (Liposarcus pardalis), espécies de hábitos sedentários. O GLM explica apenas $8 \%$ da variabilidade do fator, sendo as principais fontes de variação o mercado de desembarque, o mês da captura e a arte de pesca utilizada (Tab. 5). Porém o baixo valor de $\mathrm{R}^{2}$ indica que há outras variáveis, não consideradas no modelo, que afetam também a captura deste grupo de espécies.

A Figura 2 apresenta um esquema sumário dos resultados obtidos na análise multi-variada, destacando os grupos de espécies representados pelos quatro primeiros fatores e aquelas variáveis que mais afetaram as suas pescarias.

\section{DISCUSSÃO}

A cidade de Santarém é o porto pesqueiro mais importante do Médio Amazonas. A atividade pesqueira na região tem características particulares. Pela grande diversidade de espécies alvo, técnicas e tipos de embarcações, as pescarias na 
Tabela 6. Comparação múltipla das médias de captura/viagem dos primeiros 5 fatores, de aordo com o test de Duncan. Letras diferentes indicam diferenças significativas entre as médias dos grupos, onde $\mathrm{A}>\mathrm{B}>\mathrm{C}>\mathrm{D}>\mathrm{F}$. $\mathrm{N}=$ número total de desembarques com a característica indicada.

\begin{tabular}{|c|c|c|c|c|c|c|}
\hline VARIAVEL & $N$ & FATOR 1 & FATOR 2 & FATOR 3 & FATOR 4 & FATOR 5 \\
\hline \multicolumn{7}{|l|}{ Embarcaçăo } \\
\hline Canod & 274 & D & D & A & C & $A B$ \\
\hline c. motorizada & 62 & D & c & c & $B C$ & A \\
\hline B. pescador & 331 & C & C & B & A & $A B$ \\
\hline B. comprador & 90 & B & A & BC & A & $A B$ \\
\hline B. misto & 283 & A & $A B$ & A & B & B \\
\hline B. carga/inha & 108 & D & BC & C & B & - \\
\hline \multicolumn{7}{|l|}{ Distância } \\
\hline 1 & 599 & C & B & C & B & BC \\
\hline 2 & 508 & B & A & $c$ & B & $c$ \\
\hline 3 & 72 & A & A & B & A & B \\
\hline 4 & 29 & $c$ & B & A & c & A \\
\hline \multicolumn{7}{|l|}{ Periodo } \\
\hline Dia & 353 & c & B & A & A & A \\
\hline Nolte & 912 & B & C & B & c & B \\
\hline Dia/Nolte & 215 & A & A & C & B & A \\
\hline \multicolumn{7}{|l|}{ Ambiente } \\
\hline Rlo & 280 & A & $A B$ & A & C & A \\
\hline lgapó & 44 & B & B & A & $B C$ & A \\
\hline lgarcpé & 48 & A & A & B & B & A \\
\hline Lago & 370 & B & A & $B^{\prime}$ & A & A \\
\hline \multicolumn{7}{|l|}{ Arte } \\
\hline Bubula & 492 & A & $B C$ & A & $C D$ & BC \\
\hline Espinhel & 648 & B & $D$ & B & $F F$ & $c$ \\
\hline Linha & 192 & c & D & B & $D F F$ & C \\
\hline Mahadelra & 1759 & $D$ & B & C & $A B$ & $A B$ \\
\hline Miqueira & 1524 & D & D & B & A & $A B$ \\
\hline Lance & 15 & D & A & c & $F$ & $A B C$ \\
\hline Tarrafa & 527 & $\mathrm{~F}$ & C & A & CDF & $B C$ \\
\hline Mals de uma & 1449 & D & B & B & $B C$ & A \\
\hline \multicolumn{7}{|l|}{ Mês } \\
\hline 1 & 415 & FF & B & $\mathrm{F}$ & B & B \\
\hline 2 & 341 & $\mathrm{~F}$ & $B C$ & $\mathrm{~F}$ & A & B \\
\hline 3 & 441 & $\mathrm{~F}$ & B & $\mathrm{F}$ & B & B \\
\hline 4 & 502 & $\mathrm{~F}$ & $\mathrm{~F}$ & C & C & A \\
\hline 5 & 557 & DF & $F$ & $A B$ & $C D$ & B \\
\hline 6 & 406 & $D$ & FF & $B C$ & $c$ & B \\
\hline 7 & 469 & C & DF & $B C D$ & B & c \\
\hline 8 & 841 & B & D & $C D F$ & DF & B \\
\hline 9 & 873 & A & D & DF & $F$ & B \\
\hline 10 & 737 & C & B & $B C$ & $\mathrm{~F}$ & C \\
\hline 11 & 607 & DF & A & CDF & $\mathrm{F}$ & C \\
\hline 12 & 417 & A & A & B & B & - \\
\hline \multicolumn{7}{|l|}{ Mercado } \\
\hline Edlfrigo & 939 & A & c & B & $F$ & C \\
\hline Modelo & 1663 & c & A & D & A & B \\
\hline Uruará & 3370 & B & $A B$ & $c$ & $D$ & $B$ \\
\hline 2000 & 634 & c & B & A & c & A \\
\hline
\end{tabular}


região podem ser consideradas de caráter bastante artesanal. No entanto, com um rendimento anual de mais de 4.000 t/ano e capturas médias de quase $400 \mathrm{~kg}$ /viagem, Santarém ocupa provavelmente um dos primeiros lugares entre as cidades da Amazônia brasileira, ao lado de ManausAM, Belém-PA e Tabatinga-AM (BARTHEM, 1995, ISAAC \& BARTHEM, no prelo).

A atividade pesqueira profissional do Estado do Amazonas, cuja produção é desembarcada em Manaus é de maior escala que a do Médio Amazonas. Em meados da década de 80 o desembarque em Manaus atingiu por volta dos 30.000 t/ano (MERONA \& BITTENCOURT, 1988). No período 1976-1978, a captura média era de pouco mais de $4 \mathrm{t} /$ viagem (PETRERE, 1985a), uma ordem de magnitude maior do que o rendimento observado em Santarém. As embarcações podem viajar a locais até $3.000 \mathrm{~km}$ de distância de Manaus e as viagens podem durar até 3 meses (PETRERE, 1992). Durante a seca, quando muitos peixes Characiformes saem das várzeas para o canal do rio, ocorre a sua captura, em locais próximos de Manaus. À diferença do Médio Amazonas, durante esta época a frota de pesca de Manaus utiliza freqüientemente redes de cerco. Este apetrecho facilita a captura de peixes que formam cardumes, como o jaraqui, que constitui $40 \%$ do total desembarcado em Manaus (BARTHEM, 1995). As redes de cerco, são muito custosas, de difícil operação e, até pouco tempo atrás, eram proibidas pela legislação pesqueira (ISAAC et al., 1994), razões pelas quais não fazem parte das artes utilizadas nas pescarias do Médio Amazonas. Durante a enchente a frota do Estado do Amazonas desloca-se para locais mais distantes de Manaus e as pescarias tem como alvo a captura do tambaqui com malhadeiras (PETRERE, 1985a; MERONA \& BITTENCOURT, 1988).

$O$ desembarque na cidade de Belém, atinge aproximadamente 20.000 t/ano (BARTHEM, MPEG, com. pess.). No estuário do rio Amazonas, as pescarias diferenciam-se das dos outros locais da Amazônia, observando-se uma safra de peixe de água doce no inverno e outra de peixe de água salgada no verão. Destaca-se a pesca da piramutaba, a única pescaria de água doce da Amazônia com caráter industrial, exercida com barcos de ferro e redes de arrasto, que atinge uma produção de aproximadamente $13.000 \mathrm{t} / \mathrm{ano}$ (IBAMA, 1994).

$\mathrm{O}$ desembarque de pescado na cidade de Tabatinga foi estimado em torno de $8.500 \mathrm{t}$ em 1988 (SUDEPE, 1987). Como em Santarém, a pescaria mais importante de Tabatinga tem como alvo os peixes lisos, particularmente a dourada. As frotas pesqueiras transitam entre as fronteiras de Brasil, Peru e Colômbia (BAYLEY, 1981), de modo que o desembarque em Tabatinga está mais relacionado com o preço do pescado em cada lado da fronteira do que com o país em que o pescado foi capturado (BARTHEM, 1995).

A análise dos dados de desembarque realizada através das técnicas de estatística multivariada permitiu explorar de forma integrada as características da pesca na 
região do Médio Amazonas. Dos parâmetros que caracterizam a atividade pesqueira, os que mais afetararam foram o mercado de desembarque, as artes de pesca, o mês e o ambiente de captura. Outras características, como quantidade de gelo e combustível carregado pelo barco, número de pescadores, duração da viagem e hora da pescaria, embora significantes para alguns fatores, tiveram um efeito pequeno (menos de $5 \%$ da variabilidade explicada pelo modelo GLM). 0 s fatores surgem da combinação das características do comportamento dos peixes, com as adaptações dos pescadores às condições climáticas regionais e com as preferências do mercado de consumo do pescado, refletindo a estrutura das pescarias e a dinâmica do sistema, nos seus aspectos ecológicos, tecnológicos e econômicos. Assim, através dos fatores podemos detectar a existência de grupos de espécies mais ou menos definidos, que caracterizam pescarias diferentes, que poderiam ser resumidas da seguinte forma: (Fig. 2)

- Grandes bagres, alvo de pesca para a exportação (FATOR1).

- Pesca de entre-safra, realizada nos lagos em parte para exportação em parte para o consumo local (FATOR4).

- Peixes de escamas de hábitos sedentários e/ou migradores, alvo da pesca comercial de pequena escala e de relevância no mercado local (FATOR2, FATOR3 e FATOR5), que inclui espécies importantes, como o tambaqui e pirarucu capturados nos lagos, ou jaraqui e pacu capturados nos rios.

As variáveis incluídas no modelo de co-variância, explicaram as características da pescaria representada pelo FATOR1 mais do que as de qualquer outro, fato indicado pelo alto valor de R2 neste caso. Este fator espelhou a maior parte da produção pesqueira de Santarém que destina-se à exportação. Trata-se de peixes da ordem Siluriformes, bagres de grande porte (principalmente do gênero (Brachyplatystoma), capturados durante a denominada 'safra do peixe liso' na estação seca (McGRATH et al., 1993a). A captura destas espécies na calha do rio exige a utilização de artes como a bubuia ou o espinhel e viagens relativamente longas, a locais mais ou menos distantes de Santarém, que requerem maiores insumos. Para tal, os pescadores contam com financiamento por parte do comprador do pescado. Quase a metade da produção total de Santarém é comprada pelo frigorífico Edifrigo (RUFFINO \& ISAAC, 1994), que por isso apareceu como a característica mais importante, definindo este fator. Como a população humana da Amazônia central não tem o costume de se alimentar deste tipo de peixes, após o beneficiamento (limpeza, filetagem, congelamento, embalagem, etc.) e transporte, boa parte da produção é vendida nos estados do sul e nordeste do país (RUFFINO \& CARVALHO, 1995).

Entre as safras do peixe liso e como uma alternativa à pesca dos bagres existe um tipo de pescaria que foi bem definida através do FATOR4. Desenvolve-se em ambientes de lagos e durante o inverno, época na qual a operação das embarcações de pesca no 


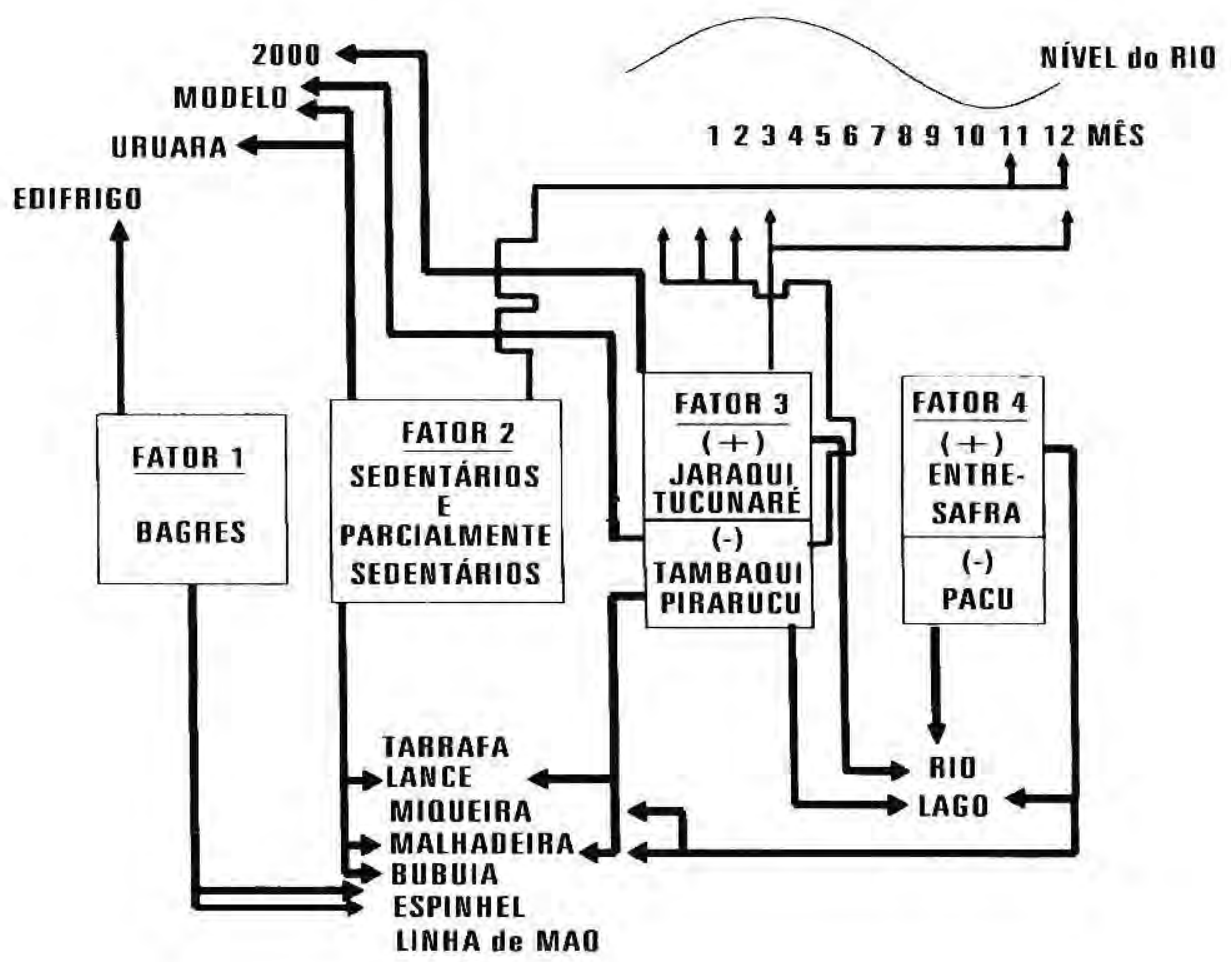

Figura 2. Representação gráfica sumária dos resultados obtidos com análise de fatores e o GLM para a pesca na região do Médio Amazonas, desembarcada em Santarém em 1993, As flechas assinalam as correlações mais fortes entre os fatores e as variáveis categóricas.

rio é difícil e pouco produtiva. É realizada por embarcações comerciais de médio e grande porte e utilizando miqueiras e malhadeiras. Por suas características, esta atividade origina conflitos entre os pescadores comerciais e os moradores das comunidades ribeirinhas dos lagos, que consideram os lagos como área privada, de pesca exclusiva (RUFFINO \& ISAAC, 1994). A pesca de entre-safra é caracterizada pela dominância do mapará e da pescada. O mapará, é um peixe de baixo valor econômico e, por ser também um bagre, é pouco apreciado para o consumo pelas populações locais, por isso boa parte da produção destina-se também à exportação para outros estados do Brasil, seco ou salgado. O mapará é também pescado muito intensamente durante a sua migração reprodutiva, no rio Tocantins, onde suspeita-se de sobreexploração devido ao declínio das capturas nos últimos anos (MERONA, 1993). Muitos pescadores desta região viajam atualmente ao Médio Amazonas para a sua captura, que ocorre principalmente nas regiōes centrais dos grandes lagos de várzea, onde o mapará passa o inverno, alimentando-se de plâncton na coluna d'água (CARVALHO et al., 1978; CARVALHO, 1980; CARVALHO \& GOULDING, 1985; ALCÂNTARA NETO, 1994). As pescadas, que ocorrem 
também no FATOR4, habitam esses lagos de várzea durante todo o ano, onde alimentam-se e reproduzem-se (WORTHMANN, 1982). As outras duas espécies que ocorrem no fator, aracu (Schizodon spp. e Leporinus spp.) e fura-calça (Pimelodina spp.), também passam boa parte do ano em ambientes lacustres. À diferença do mapará que é comercializado no frigorífico Edifrigo, a comercialização de pescada, aracu e fura-calça, ocorre predominantemente no mercado local, para consumo da população de Santarém (RUFFINO \& ISAAC, 1994), razão pela qual neste fator o mercado de comercialização não teve uma posição importante no modelo.

Outros peixes de escama, (principalmente Characiformes) são também comercializados nos mercados para o consumo local (RUFFINO \& ISAAC, 1994). 0 segundo, terceiro e quinto fator destacam diferentes aspectos das pescarias que tem por alvo essas espécies. Trata-se de uma pesca de menor escala, muito diversa, realizada com diferentes artes de pesca e em locais variados. Algumas espécies formam parte de mais de um fator. Por isto, estes três fatores foram de interpretação mais complexa, e as variáveis da pesca consideradas no GLM explicaram uma parte relativamente pequena da variação dos desembarques destas espécies. Isto reflete as características altamente flutuantes da pesca artesanal da região. $\mathrm{O}$ segundo, terceiro e quinto fator diferenciam-se entre si por algumas características, tais como a época do ano, a arte utilizada ou o ambiente em que ocorrem as pescarias.

OFATOR2 reflete principalmente a captura de peixes sedentários no final do período da seca. Juntamente com os peixes sedentários ocorreram algumas espécies de peixes migradores (tambaqui, curimatã e surubim). Durante o início das enchentes, a maioria dos adultos de peixes com hábitos migradores deslocam-se para as novas regiões de lagos, savanas e florestas alagadas, onde encontram renovadas fontes de alimento aquático ou acesso a frutos, sementes, artrópodes e outros ítens de origem terrestre, assim como refúgio e proteção dos predadores (JUNK et al., 1989). Nesta época, os pescadores também transladam-se para estas áreas, utilizando as malhadeiras nas suas operações de pesca. Este fator não apresentou uma boa diferenciação entre lago e rio, talvez justamente devido ao fato da transição das pescarias entre estes dois ambientes. A pescaria do tambaqui, como definida através do FATOR2 no final da estação seca e início das chuvas deve estar indicando àquela dirigida aos indivíduos adultos desta espécie que ainda estão no rio, apresentam gônadas maturas e deverão desovar no fim do ano (ISAAC et al, no prelo). Os locais de maiores capturas, afastados da cidade de Santarém, coincidem com as observações dos pescadores sobre os locais de desova da espécie. Por outro lado, outros aspectos da pesca do tambaqui estão apresentados no FATOR3 negativo, onde esta espécie apareceu numa pescaria conjunta com o pirarucu, desta vez claramente vinculada ao ambiente dos lagos. $\mathrm{O}$ tambaqui permanece vários anos da 
sua vida nos lagos de várzea, antes de sua primeira maturação sexual, que ocorre quando os indivíduos atingem entre 50 e $55 \mathrm{~cm}$ de comprimento total (GOULDING \& CARVALHO, 1982; ISAAC et al., no prelo). Os baixos valores das médias do FATOR3 negativo nos períodos fevereíro-abril e agosto-novembro representam as épocas de maior captura de tambaqui e pirarucu (Tab. 2). Estas espécies são preferencialmente comercializadas no Mercado Modelo, onde freqüentemente são observados indivíduos pequenos, abaixo do tamanho permitido pela legislação (55 $\mathrm{cm}$ para tambaqui e $150 \mathrm{~cm}$ para pirarucu) (ISAAC et al. 1994; RUFFINO \& ISAAC, 1994). Justamente, a correlação deste fator com os ambientes lacustres e os meses de março a abril, indicaria que a pescaria assinalada pelo FATOR3 negativo, é aquela que captura indivíduos juvenis de tambaqui,coincidindo com a descrição de RUFFINO \& ISAAC (1994). A predominância de indivíduos pequenos nas capturas e as taxas de crescimento relativamente baixas apresentadas pelo tambaqui sugerem uma situação de sobrepesca de crescimento para esta espécie na região (ISAAC \& RUFFINO, 1996), fato que também é suspeitado para o pirarucu (BAYLEY \& PETRERE, 1989). A pesca de peixes pequenos ocorre com preferência em locais mais próximos da cidade de Santarém (ISAAC \& RUFFINO, 1996), região com predominância de grandes lagos de várzea, onde habitam os juvenis, e onde talvez, devido à grande pressão de pesca, não há tanta abundância de peixes grandes como antigamente, segundo lembram os velhos pescadores da região.

No fim do período das chuvas boa parte dos Characiformes que se encontram na procura de alimento nas várzeas e florestas alagadas, abandonam estes ambientes para iniciar uma migração dispersiva pela calha do rio, denominada migração do "peixe gordo" (RIBEIRO, 1983; RIBEIRO \& PETRERE, 1990). Algumas espécies, como o jaraqui, iniciam esta migração mesmo antes do início da descida das águas e a finalizam depois que as outras (GOULDING, 1979; PETRERE, 1985b). A pesca comercial atua intensamente sobre os cardumes desta espécie, concentrados no rio, durante o início e fim desta migração. O FATOR3 positivo reflete claramente a pescaria do jaraqui, que ocorre com grande intensidade, no fim do inverno, mês de maio no ambiente de rio, e posteriormente novamente, em menor escala, no mês de dezembro, no início do inverno. A ocorrência das outras espécies que acompanham o jaraqui no FATOR3 positivo (tucunaré, acará, charuto) pode estar vinculada ao padrão temporal das suas capturas, que também apresentam uma curva bimodal, sendo um pico em dezembro e outro relativamente menor em maio. Outra espécie que também é capturada durante a sua migração no rio é o pacu, cuja pescaria foi definida pelo FATOR4 negativo.

No FATOR5 ocorrem dois grupos opostos de espécies que poderiam ser caracterizados como espécies sedentárias (acarí-bodo, aruanã e traíra) e migradoras (pirapitinga, charuto, branquinha), porém o baixo coeficiente de determinação do fator em relação às variáveis da pesca consideradas, não permitem tirar maiores 
conclusões sobre este grupo.

As atividades da pesca comercial da região do Médio Amazonas, podem ser caracterizadas, e em parte classificadas, de acordo com diferentes critérios e pontos de vista (BAYLEY \& PETRERE, 1989; BARTHEM et al., no prelo), a saber:

Critério 1- Estratégias de vida das espécies alvo. Delimita por um lado espécies de peixes sedentários e por outro espécies de peixes migradores. Cirtério 2- Ecologia das espécies, ambiente da pesca e ciclo hidrológico do rio. Delimita a pesca nos canais dos rios e a pesca nos lagos de várzea $\mathrm{e}$ áreas alagadas.

Critério 3- Mercado de consumo de pescado e tecnologia de pesca. Delimita, por um lado, a produção destinada a exportação e por outro a produção provinda de pescarias de menor escala $\mathrm{e}$ destinada ao consumo local da cidade de Santarém e arredores.

Os padrões de pesca observados respondem a uma interação simultânea destes critérios que resultam, às vezes, de difícil interpretação, mas que de alguma forma refletem a complexidade do sistema como um todo. A análise multivariada deste estudo permitiu destacar certos padrões da estrutura das pescarias. Além disso, pode ser identificado um certo cronograma das pescarias, mais ou menos definido pelos critérios acima mencionados. Assim, no início do ano, quando o rio está subindo, domina a pesca de entresafra, nos lagos (FATOR4 positivo), seguida pela pesca do tambaqui (pequenos) e pirarucu principalmente no mês de abril (FATOR3 negativo), também nos lagos. No início das migrações dos Characiformes, o jaraqui (FATOR3 positivo) torna-se o alvo principal dos pescadores, que se deslocam para o rio. Nos meses do verão destaca-se a safra dos bagres (FATOR1) e posteriormente a captura do pacu (FATOR4 negativo) no rio. Para o fim do ano ocorre novamente a transição de ambientes e peixes alvo, sendo definida a pescaria de espécies sedentárias e alguns migradores (FATOR2) tanto nos rios como nos lagos (Fig.3).

A caracterização de grupos diferentes de peixes nas pescarias do Médio Amazonas poderia também servir como base para o ordenamento pesqueiro. Um dos problemas mais chamativos na região tem sido a ocorrência de graves conflitos sociais, decorrentes da utilização do recurso por vários grupos de usuários (RUFFINO \& ISAAC, 1994). $\mathrm{Na}$ tentativa de estabeleceram regras informais, para diminuir o esforço de pesca nos lagos de várzea e manter a produtividade do ambiente, um número crescente de comunidades ribeirinhas tem elaborado acordos de pesca com normas que envolvem uma ou várias restrições sazonais ou permanentes (RUFFINO, 1994).

$\mathrm{O}$ conhecimento, experiência e iniciativa das comunidades ribeirinhas no Médio Amazonas para a criação das chamadas "reservas de lago" pode ser considerada como uma verdadeira alternativa para o gerenciamento pesqueiro local, McGRATH et al. (1993b). Para espécies essencialmente sedentárias, como o pirarucu e tucunaré, que amadurecem e reproduzem dentro de áreas relativamente restritas, assim como para a proteção das 


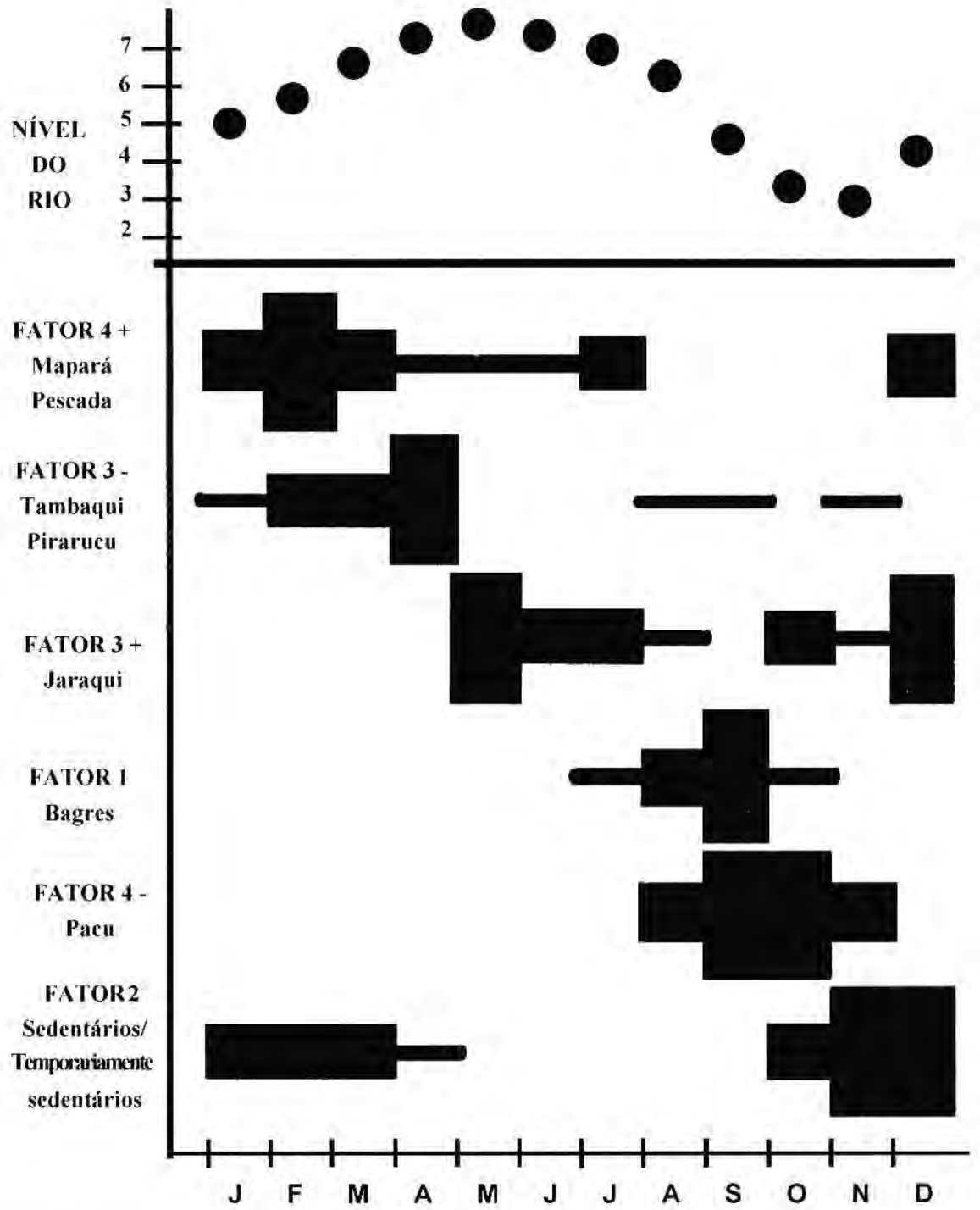

Figura 3. Cronograma de pesca na região do Médio Amazonas definida pela análise multivariada 
fases juvenis dos caracoideos migradores como o tambaqui, a reserva de lago é provavelmente uma unidadede manejo adequada. Porém esta medida será menos efetiva para espécies de peixes adultos que migram entre lagos e rios e ainda menos influirá no manejo dos grandes bagres, principal alvo da pesca comercial na região (FATOR1).

RUFFINO et al. (no prelo) discutem a necessidade de se estabelecer uma estratégia de manejo para os grandes bagres migradores. Os mesmos autores salientam que os jovens dessas espécies são encontrados no estuário e os adultos, aptos à reprodução, no Alto Amazonas em território brasileiro, colombiano e peruano, indicando que o mesmo estoque utiliza ambientes muito distantes para completar o seu ciclo biológico, percorrendo distâncias além de 3.500 $\mathrm{km}$. A calha do rio Amazonas constitui um ambiente importante para os bagres predadores, pois além de ser a via natural de dispersão das larvas para o estuário, é o ambiente onde os adultos encontram suas presas.

O melhor conhecimento do ciclo de vida e distribuição geográfica dos grandes bagres é de fundamental importância para a implantação de uma política para o gerenciamento da exploração deste recurso natural. A situação é ainda mais complexa quando o estoque é compartilhado por frotas de diferentes países. Desse modo, o manejo destas espécies somente será possível através de uma política de manejo macroregional que integre normas de ordenamento nos três países vizinhos.
Os autores agradecem ao IBAMA, GTZ e CNPq pelo apoio logístico e aporte financeiro para o levantamento dos dados, bem como aos funcionários do Projeto IARA/IBAMA em Santarém pela coleta e digitação dos dados que permitiram a elaboração deste trabalho.

\section{Bibliografia Citada}

ALCÂNTARA NETO, C.P. 1994. Ecologia e pesca dos maparás, Hypophthalmus spp. (Siluriformes, Hypophthalmidae) no Lago Grande de Monte Alegre, Baixo Amazonas-PA. Dissertação de Mestrado. Universidade Federal do Pará/Museu Paraense Emílio Goeldi, Belém, 141 p.

BARTHEM, R.B. 1995. Development of commercial fisheries in the Amazon Basin and consequences for fish stocks and subsistence fishing. In: CLÜSENERGODT, M.; SACHS, I. (eds.). Brazilian perspectives on sustainable development of the Amazon region. UNESCO, Man and the Biosphere Series, 15:175-204.

PETRERE JR., M.; ISAAC, V.J.; RIBEIRO, M.C.L.B.; McGRATH, D.G.; VIEIRA, I.J.A.; VALDERRAMA, M. (no prelo). A pesca na Amazônia: Problemas e perspectivas para o seu manejo. Workshop Manejo da Vida Silvestre para a Conservação na América Latina. Belém, PA, Brazil. 0305 February 1992.

BAYLEY, P.B. 1981. Fish yield from the Amazon in Brazil: comparisons with African river yields and management possibilities. Trans. Am. Fish. Soc., 110:351-359.

PETRERE JR., M. 1989. Amazon Fisheries: Assessment Methods, Current Status and Management Options. In: DODGE, D.P. (ed.). Proceedings of the International Large River Symposium, Can. Spec. Publ. Fish. Aquat. Sci., 106: 385-398.

CARVALHO, F.M. 1980. Alimentação do mapará (Hypophthalmus edentatus Spix, 1829) do Lago do Castanho, Amazonas (Siluriformes, Hypophthalmidae). Acta Amazonica, 10(3):545-555. 
CARVALHO, J.L.; COELHO, A.C.; TODA, E. 1978. Hábito alimentar do mapará, Hypophthalmus perporosus Cope 1878 (Pisces Hypophthalmidae). Boletim da Faculdade de Ciências Agrárias do Pará, (10);17-35.

CARVALHO, M.L.; GOULDING, M. 1985. On the feeding ecology of the catfish Hypophthalmus fimbriatus in the blackwater Rio Negro of the Amazon Basin. Revista Brasileira de Zoologia, 3(1):33-41.

GOULDING, M. 1979. Ecologia da pesca do rio Madeira. CNPq-INPA, Manaus, 172 p.

; CARVALHO, L.M. 1982. Life history and management of the tambaqui (Colossoma macropomum, Characidae), an important Amazonian food fish. Revista Brasileira de Zoologia, 1(2):107-133.

IBAMA. 1994. Camarão norte e piramutaba. Relatórios das reuniões dos grupos permanentes de estudos-GPE's. Piramutaba. IBAMA. Coleção Meio Ambiente. Série Estudos Pesca, (9): 77-150.

1995. Projeto IARA - Administração dos Recursos Pesqueiros do Médio Amazonas (Pará e Amazonas). IBAMA. Coleção Meio Ambiente. Série Estudos Pesca, 15: 96 p.

ISAAC, V.J. \& BARTHEM, R.B. (no prelo) Os recuros pesqueiros da Amazônia brasileira. Boletim do Museu Paraense Emílio Goeldi. ISAAC, V.J.; ROCHA; V.L.C.; MOTA, S. 1994. Algumas considerações sobre a legislação da "piracema" e outras restrições da pesca da região do Médio Amazonas. pp 187-211. In: FURTADO, L.; LEITÃO, W. \& MELLO, A.F. (eds.). Povos das Águas realidade e perspectiva na Amazônia. MCT/CNPq/MPEG, Belém, $292 \mathrm{p}$.

ROCHA, V.L.C.; MOTA, S. (no prelo). Ciclo reprodutivo de algumas espécies de peixes comerciais do Médio Amazonas. IBAMA. Coleção Meio Ambiente, Série Estudos Pesca..

RUFFINO, M.L. 1996(no prelo). Population dynamics of tambaqui, Colossoma macropomum Cuvier 1818, in the Lower Amazon, Brazil. Fisheries
Management and Ecology, (3):

JEFFERS, J.N.R 1978. An introduction to system analysis: with ecological applications. E. Arnold Publ., London, 198 p.

JUNK, W.P.; BAYLEY, P.; SPARKS, R. 1989. The flood pulse concept in riverfloodplain systems. Can. Spec. Publ. Fish. Aquat. Sci., 106:110-127.

KIM, J. O.; MUELLER, C.W. 1978. Fator Analysis. Statistical methods and practical issues. Quantitative applications in social sciences. 14 Sage Univ., 88 p.

LEFEBVRE, J. 1976. Introduction aux analyses statistiques multidimensionalles. Masson, Paris, 219 p.

MCGRATH, D.G.; CASTRO, F; FUTEMMA, C.; AMARAL, B.D,; CALABRIA, J. 1993a. Fisheries and the evolution of Resource Management on the Lower Amazon Floodplain. Humam Ecology, 21(2):167-195.

.....; CASTRO, F; FUTEMMA, C.R.; AMARAL, B.D.; CALABRIA, J.A. 1993b. Manejo Comunitário da Pesca nos lagos de várzea do Baixo Amazonas. pp. 213-229. In: FURTADO, L; LEITÃO, W. \& MELLO, A.F. Povos das Águas: realidade e perspectiva na Amazônia. MCT/ CNPq/MPEG, Belém, 292 p.

MERONA, B. 1993. Pesca e ecologia dos recursos aquáticos na Amazônia. pp. 159-185. In: FURTADO, L.; LEITÃO, W. \& MELLO, A.F. Povos das Águas: realidade e perspectiva na Amazônia. MCT/CNPq/MPEG, Belém, 292 p.

BITTENCOURT, M.M. 1988. A pesca na Amazônia através dos desembarques no mercado de Manaus: Resultados preliminares._Memoria da Sociedade de Ciencias Naturales La Salle, 48 , supl.:433-453.

; BITTENCOURT, M.M. 1991. La pêche artisanale en Amazonie Centrale: approaches et difficultés. In: DURAND, J.R.; LEMOADLE, J. \& WEBER, J. (eds.). La Recherche Face a la Pêche Artisanele. Symposium International ORSTON-IFREMER, ORSTON. Tommo I: 433-441. 
MILSTEIN, A. 1993. Fator and canonical correlation analyses: basic concepts, data requirement and recommended procedures. In: PREIN, M.; HULATA, G. \& PAULY, D. (eds.). Multivariate methods in aquiculture research: case studies of tilapias in experimental and commercial systems. ICLARM Studies and Reviews 20.

PETRERE JR., M. 1978a. Pesca e esforço de pesca no estado do Amazonas, I- Esforço e captura por unidade de esforço. Acta Amazonica, 8(3):439-454.

.... 1978b. Pesca e esforço de pesca no estado do Amazonas. II. Locais e aparelhos de captura e estatística de desembarque. Acta Amazonica, 8(3): Suplemento 2:1- 54.

; 1985a. A pesca comercial no rio SolimõesAmazonas e seus afluentes: análise do pescado desembarcado no Mercado Municipal de Manaus (1976-1978). Ciência e Cultura, 37 (12):1987-1999.

...; 1985b. Migraciones de peces de agua dulce en America Latina: Algunos comentarios. COPESCAL Doc. Ocas., (1):17 p.

.....; 1992. Pesca na Amazônia. p. 72-78. In: Secretaria de Estado de Ciência, Tecnologia e Meio Ambiente-PARÁ. SIM DAMAZÔNIA, Seminário Internacional Sobre Meio Ambiente, Pobreza e Desenvolvimento da Amazônia. Anais: Belém. PRODEPA. $567 \mathrm{p}$.

PREIN, M.; MILSTEIN, A. 1988. Techniques for handling large pond and farm datasets. Aquabyte, 1(2):4-5.

RIBEIRO, M.C.L.B. 1983, Ecologia das migrações dos jaraquis no rio Negro. Dissertação de Mestrado. INPAFUA, Manaus. 192 p.

...; PETRERE JR., M. 1990. Fishery ecology and management of the jaraqui (Semaprochilodus teaniurus, S. insignis) in Central Amazonia. Regulated Rivers: Research and Management, 5:195-215.
RUFFINO, M.L. 1994. Desenvolvimento Pesqueiro no Baixo Amazonas. Paper presented on Confenence about Diversity, Development and Conservation of the Amazon Flooplain. 12-15 dez 1994. Macapá/APBrasil.

; BARTHEM, R.B.; FISCHER, C.A. (no prelo). Problemas para o manejo dos bagres migradores na Amazônia. IBAMA. Coleção Meio Ambiente. Série Estudos de Pesca.

; CARVALHO, N.L.A. 1995. Aspectos da conservação, armazenamento e comercialização do pescado. In: Anais da $2^{\circ}$ Conferência AIM na América Latina: "Saúde e Atenção à Saúde na Região Amazônica". AIM/Fundação Esperança, Santarém, p. 99-107.

; ISAAC, V.J. 1994. The fisheries of the Lower Amazon: Questions of management and development. Acta Biologica Venezuelica, 15(2):37-46.

SAS, 1987. SAS user's guide: statistics. Version 6 Edition. SAS Inst. Inc., Cary, NC.

SCHUEMER, R; STRÖHLEIN, G.; GOGOLOK, J. 1990. Datenverarbeitung und statistische Auswertung mit SAS. Band II: komplexe statistische Analysverfahren. G. Fischer Verlag, Stuttgart, $437 \mathrm{p}$.

SEAL, H.L. 1964. Multivariate statistical analysis for biologist. Mathuen, London, 209 p.

SMITH, N.J.H. 1979. A Pesca no rio Amazonas. CNPq/INPA. 154 p.

SUDEPE. 1987. Diagnóstico do setor pesqueiro do Estado do Amazonas. SUDEPE, (mimeo).

.... 1988. Diagnóstico do setor pesqueiro do Estado do Pará. SUDEPE, (mimeo).

WORTHMANN, H.O. 1982. Aspekte der Biologie zweir Sciaenidenarten, der Pescadas Plagioscion squamosissimus (Heckel) una Plagioscion montei (Soares) in verschiedenen Gewässertypen Zentralamazonien. Ph.D. Thesis. Univ. Kiel, Germany, 176 p. 